\title{
A PROPOSED MODEL FOR CLINICAL NURSING EDUCATION AND TRAINING IN SOUTH AFRICA
}

The Nursing Education Stakeholders (NES) Group

CPAS, DENOSA, FUNDISA, NEA, Nurse Managers, PHEPSA, SANC

\begin{abstract}
The Department of Health hosted a Nursing Summit in April 2011. The purpose of the Summit was to revitalise the nursing profession for a health life for all South Africans. The Summit afforded the nursing profession an opportunity to reflect on issues of central concern to the profession and health sector where reforms were scheduled to take place. It also was an opportunity to share ideas and energy relating to the long-term challenges confronting the nursing workforce in the health sector. The Summit considered seven themes, namely education and training; resources in nursing; professional ethos; governance, leadership, regulation and policy; positive practice environment; compensation and benefits; and nursing human resources for health. The Summit concluded with a Compact summarising the recommendations made which will be developed into a strategic plan by a Ministerial Task Team appointed to perform this duty.
\end{abstract}

Keywords: "Type 3 - 5 keywords."

\section{Preamble}

There is global evidence to support the fact that effective clinical education and training contribute to quality nursing education and that both lead to improved patient outcomes (Al Kandari, Vidal \& Thomas, 2009; Cowan, Norman \& Coopamah, 2009). At their meeting in September 2010 and in line with international trends, the Nursing Education Stakeholders - consisting of representatives from CPAS, DENOSA, FUNDISA, NEA, Nurse Managers Forum, PHEPSA and SANC - identified the clinical education and training of nurses in pre-registration programmes as an important area of concern in improving the quality of nursing education. In October 2010 at a meeting in Pretoria, the group met to develop a discussion document for wider consultation. During this meeting a range of presentations were made to inform the group on current practices both nationally and internationally. One of the presentations involved a survey of the global and national literature in this area written over the last ten years. Based on the information provided through the presentations and the literature survey, the group developed a proposal for discussion with a wider group of stakeholders.

One of the decisions from the outset was to propose which terms should be used and to define these, so that everyone could use the same term for the same concept, thus preventing confusion and ensuring consistency. The model therefore starts with a list of definitions. Then the model components as set out in Figure 1 are described one by one. 


\section{Major precepts of the model for clinical nursing education and training}

The major precepts of the model for clinical nursing education and training suggested by the group to optimize learning in clinical settings and produce competent nurses and midwives are:

- That clinical practica for learning [experiential learning] in which students can work with patients without forming part of any service team are distinguished from clinical practica for role-taking [work-based learning], during which students do form part of the service team;

- A system of clinical preceptors is implemented which ensures a minimum level of clinical teaching and support for students during their clinical practice for role-taking;

- A designated person, the Clinical Placement Co-ordinator, manages the total clinical teaching system and ensures its functioning and quality;

- When students are doing role-taking practice, their teaching and support also form part of the job descriptions of clinical supervisors - nurses who are in charge of nursing teams where they are allocated.

- $\quad$ Students are only placed in clinical facilities where a certain level of quality of nursing care, based on clearly defined standards, is given. A Positive Practice Environment (PPE) and establishing where such a PPE is available is the responsibility of the nursing education institution (NEI).

- Nurse educators are expected to remain clinically competent in their field and be part of the clinical preceptor team.

- Clinical experts in practice are recognized and involved in classroom teaching in order to provide clinical role models for students. Such experts will be called Clinical Teaching Associates (CTA).

\section{Definitions}

1. Integration of practice and theory: competence in nursing is based on the ability to integrate knowledge from all disciplines in order to identify the problem, understand the theory related to the problem, as well as the appropriate response, treatment and care of the patient. All this integrated knowledge should then be applied in a practical event or situation in a real-life setting or simulation. Students must be assisted with this integration.

2. Patient: is a person with a healthcare need whether in a health service or not, and whether an individual or a group (e.g. a family).

3. Clinical practica for learning: students are brought into contact with patients in order to achieve specific learning outcomes and will not be individually assigned to patient care.

4. Clinical practica for role taking: students are placed in a clinical setting to learn an authentic nursing role as part of a nursing and/or multi-professional team and this always includes responsibility for patient care.

5. Clinical preceptor: a preceptor is an experienced and competent professional nurse who is positive about nursing, students and herself, who serves as a clinical teacher in the clinical setting and is employed by a Higher Education Institution (HEI).

6. Clinical supervisor: a clinical supervisor is a professional nurse working in a clinical setting who supports and develops nurses, including students, in the unit team to optimise their professional functioning and is employed by the health service authority. 
7. Clinical placement co-ordinator (CPC): a registered nurse who develops and maintains a system of optimal placement of students from all programmes in a specific $\mathrm{HEI}$ in clinical facilities based on negotiated MOUs and good inter-agency relationships that allows for students to achieve programme outcomes and assist health services to maintain good quality care.

8. Clinical Teaching Associate (CTA): a specialist registered nurse who is appointed in an honorary capacity by an NEI based on an MOU with the service facility to enrich the theoretical teaching and assessment of their students and enhance the capacity of the academic staff.

Figure 4.1 Proposed model for clinical nursing education and training

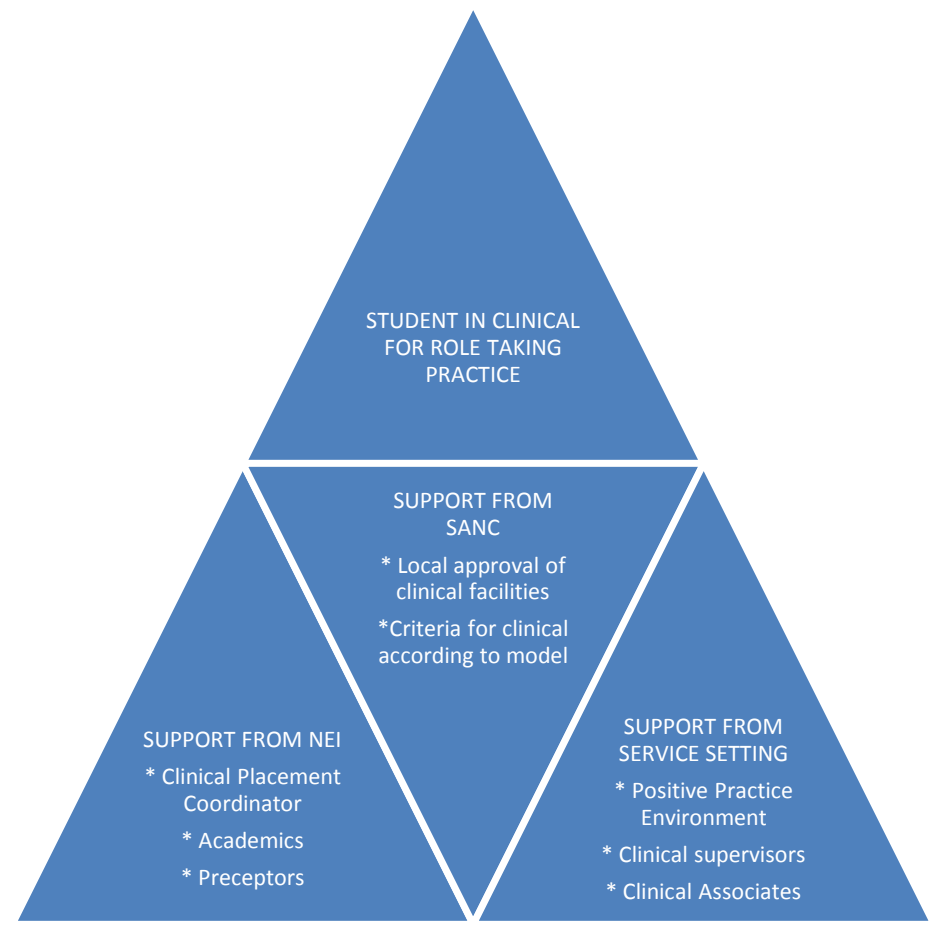

\section{Components of the model for clinical nursing education and training}

As illustrated in Figure 1, clinical nursing education and training involves four major stakeholders - the student, who is the focus of the activities, the health system in which clinical learning takes place, the nursing education institution responsible for the educational programme of the student, and the regulatory body which sets the standards for practice and education. The responsibility of each of these will now be described.

\section{Educators}

Nurse educators are attached to the Nursing Education Institution and take direct responsibility for the quality of the clinical learning of students. 


\section{Role in clinical teaching:}

- Develop curriculum with a competency focus;

- $\quad$ Responsible for clinical teaching and assisting students, through their teaching approaches, so that students are able to integrate theory with practice;

- Model clinical competence in an area of nursing;

- Work (not only observe) in the clinical area for at least 16 days (10\% of lecturers' time) per year for their own professional development and competence. The clinical area must be related to the subjects for which they are responsible.

- $\quad$ Support clinical teaching by doing research on the topic;

- $\quad$ Preceptor role demonstrated through structured clinical area visits (active participation in teaching) with preceptors and structured clinical teaching in simulation labs;

- $\quad$ Run group supervision for clinical preceptors working with the students they are teaching to ensure quality, staff development, optimal linking of theory with practice and support;

- Quality assurance of the clinical learning experiences of students.

\section{Preparation:}

- Must have an education qualification and be an expert in a substantive area of the nursing curriculum.

- Current clinical experience (Personal development time for educators) with $3-5$ years' experience.

\section{Teaching skills:}

- Appropriate nursing content and appropriate teaching methods used by educators to transfer their skills to students so as to support utilization.

- How do you teach a skill, the difference between a skills focus and a competence focus and how this is taught;

\section{Curriculum}

The curriculum is the plan for teaching and learning developed by the NEI and should make clear the position of clinical teaching and learning in the overall programme.

\section{Principles that support the clinical component in the curriculum}

- $\quad$ Practica appropriately linked in time with the theory (e.g. not theory before practice, not midwifery theory and psychiatric nursing in practice);

- Not placed for less than one month in a clinical area for role-taking practica;

- Provision is made for both clinical practica for learning and clinical practica for role- taking;

- Curricula are reviewed every 3-5 years to make sure the priorities in clinical practice are taught in theory and that the theory is appropriate for current practice. Content added to the curriculum must be balanced with content deleted. Content selected must support clinical learning outcomes.

- Work with outcomes (role and function that the person will have to fulfil) and competencies instead of outcomes and skills. 
- When planning and monitoring clinical learning periods, role functions and competencies should be the focus instead of minimum clinical hours and procedures.

- Theory should make up $30 \%$ and practica $70 \%$ of the curriculum, with clinical practica for learning comprising $30 \%$ and clinical practica for role-taking $40 \%$ of the total.

- Preparation for clinical practica is based on simulation and this may form part of the $20 \%$ allocated to clinical practice for learning.

- Pre-clinical discussions should be held where a preceptor is present to prepare students for specific practica.

- Challenge: should curricula be cut to deal only with common conditions so that we have more time to study common diseases in more depth, and should more time be spent on the application and correlation of theory and practice?

\section{Organizational structure}

Clinical nursing teaching and learning involve at least two systems (the health and education systems) working together. Such collaboration is always complex, especially when many NEls and healthcare settings are involved. It is therefore essential that an efficient and effective organizational structure be put in place to make this work smoothly.

- A dedicated person should be appointed by the NEI whose only job is to co-ordinate clinical learning experiences: i.e. a Clinical Placement Co-ordinator. This person should have a sufficiently senior position (see job description in Annexure 1).

- Clinical Preceptors should be paid by and report to the NEI. They should also be physically placed in the services and have at least an honorary appointment in the services where the NEI places students. Furthermore, they should have full access to and involvement in, service issues.

- It is recommended that there should be a ratio of 1 Clinical Preceptor for every $15-20$ students (with at least 4 sessions of 30 minutes per student per month) based on the number of students in clinical practice at the time. The purpose of a clinical preceptor is to support, help with critical thinking, link students up with a senior person in the unit to take training further, and not primarily to do assessments. (See job description.)

- Academic staff must also take up a preceptor role.

- When a Clinical Preceptor is not available, support for students should be provided by the unit staff and/or a buddy system established, run by the $4^{\text {th }}$-year students.

- Academic staff must run group supervision for preceptors working with the students they are teaching in order to ensure quality, staff development and support. This will also guarantee that the preceptor knows what is being taught in the classroom and can emphasize this in practice.

- Honorary appointment of clinical persons to take up a teaching role at the NEI should be done with at least one person per clinical field offered at the NEI to assist with teaching clinical skills and knowledge related to theory. These persons will be called Clinical Teaching Associates (CTAs) and no teaching qualification is required [see job description].

- Honorary appointments must be arranged as part of the agreement between the NEI and clinical facilities. 
- The CPC should organise a monthly Clinical Co-ordinating meeting between the NEI and all services involved so as to facilitate information sharing and discuss policies, problems, achievements, placements and other challenges (present academics, student management SRC).

- Full documentation should be maintained of

- preceptor visits

- student clinical learning

- student placement for both types of clinical exposure

- Attend meetings, keep records up-to-date.

\section{Clinical preceptors}

Clinical preceptors are the link between the NEI and the health service setting and they facilitate the clinical experience of the students.

\section{Role:}

This is a person employed by higher education institutions to interact closely with allocated groups of students in a specific facility or group of facilities to optimise the clinical learning of students in formal nursing programmes. (See the job description for the Clinical Preceptor provided in Annexure 1.)

\section{Preparation:}

- Selection must be based on the applicants' ability to demonstrate clinical reasoning, as well as on the personal attributes and skills of the practitioner such as having a positive attitude towards themselves, the student, nursing as a profession and the environment.

- Targeted short educational programme and internship.

\section{Support}

- Space in the clinical area and on campus with access to information and electronic resources;

- Recognition of the role played by the clinical facilities and the NEI;

- Group supervision and training by the NEI;

- Career ladder provision - dual possibility [back to service or obtain education and move to education].

- The NEI should support part-time education towards achieving higher education qualifications so as to make career progression possible.

\section{Clinical facilities}

By definition, clinical learning takes place in a clinical setting, where patients are being cared for, families seen, and communities supported and educated. Without an adequate variety of clinical facilities in which good quality nursing care is provided and where each individual nursing student can practise her/his role fully, it is not possible to prepare competent nurses. 


\section{Principles:}

- A NEI cannot provide good clinical learning in a dysfunctional health system: a Positive Practice Environment (PPE) is essential. Clinical teaching must be a key performance area for senior staff in PPEs in order to engender commitment.

- $\quad$ Students should be placed for role-taking practice only in identified PPEs.

- The following criteria for the selection of PPEs, based on the Government Criteria as listed as domains and (sub-domains):

- Patient Rights (respect and dignity; information provided to patients; physical access; continuity of care; reducing delays in care; emergency care; delivery of a package of services; and complaints management);

- Patient safety, clinical governance and clinical care (patient care; clinical leadership; clinical management of priority health programmes; clinical risk; infection prevention and control; adverse events);

- Clinical support services ( pharmaceutical services; clinical support services; clinical equipment and supplies; medical records; healthcare technology maintenance);

- Public health (population-based service planning and delivery; health promotion and disease prevention; disaster preparedness);

- Leadership and corporate governance (planning; strategic leadership; stakeholder representation; oversight; risk management; communication and public relations; quality improvement);

- Operational management (human resource management and development; employee wellness; financial resource management; supply chain management; transport and fleet management; information management);

- Facilities \& infrastructure (buildings and grounds; machinery and utilities; safety and security; hygiene and cleanliness; waste management; linen and laundry; food services).

- Other criteria:

- Registered Nurses and other team members must accept teaching as part of their role;

- Expertise should be developed so as to assist practitioners to modernise their practices through continuous professional development, outreach approaches for educational interventions and feedback on performance;

- Patients' perceptions and concerns should be clearly understood;

- Health systems need to be strengthened.

- The NEI and its relevant moderators should be responsible for approval of clinical facilities and not the SANC. Inspection of the utilisation of facilities can be done by the SANC during its 5-yearly inspection of the school, but the approval of new facilities to be used must be done locally by the NEI.

- Co-ordination of clinical placements should be undertaken on a provincial/regional basis with consideration of:

- The numbers of students in the programme(s) and the number of units to which they can be allocated;

- The previous commitment of a specific service facility to a specific programme; 
- Equity: all the nursing education providers should have equitable access to public health services;

- The specific needs and learning opportunities of the curriculum of each NEI, e.g. sequencing;

- $\quad$ The placement plan should be electronically available for instant and flexible updating.

\section{Suggested plan for implementation}

It was suggested that a team be appointed to champion the implementation of this model for clinical nursing education and training. The task team should consist of the NES group and two representatives from the HR at national and provincial DOH.

\section{Table 4.1 Implementation plan for the Clinical Nursing Education and Training Model}

\begin{tabular}{|c|c|c|}
\hline Activity & Responsibility & Stakeholders \\
\hline $\begin{array}{l}\text { Curriculum review in accordance with new } \\
\text { guidelines }\end{array}$ & NEI & NEI \& services \& SANC \\
\hline Update clinical experience of academics & $\mathrm{NEI}$ & NEI \\
\hline Develop curriculum for preparation of preceptors & NEI & NEI \& services \\
\hline Do research on clinical teaching and learning & NEI & NEI and services \\
\hline $\begin{array}{l}\text { Plan and implement a quality assurance plan for } \\
\text { clinical teaching and learning }\end{array}$ & $\mathrm{NEI}$ & $\begin{array}{l}\text { NEI, Preceptors, Clinical Co- } \\
\text { ordinating Committee (CCC) }\end{array}$ \\
\hline Create positions for preceptors & NEI & NEI management \\
\hline Recruit and appoint a CPC & NEI & NEI management \\
\hline Recruit and train preceptors & CC & NEI management \\
\hline Establish electronic system for student placement & CPC & NEI \\
\hline Identify PPEs for clinical placement & CPC & $\mathrm{NEI}, \mathrm{CCC}$ and $\mathrm{CPC}$ \\
\hline Identify and recruit CTAs & CPC & NEI, preceptors, services \\
\hline $\begin{array}{l}\text { Create a system of honorary appointments, PPE } \\
\text { placements and CTAs in terms of MOUs }\end{array}$ & NEI management & NEI \& services \\
\hline Develop physical infrastructure for preceptors & $\mathrm{CPC}$ & Services \\
\hline Prepare clinical facilities for new system & NEI \& Services & \\
\hline Prepare NEIs for new system & NEI & \\
\hline $\begin{array}{l}\text { Develop screening instrument for identification of } \\
\text { preceptors }\end{array}$ & NEI \& CC & Services \\
\hline $\begin{array}{l}\text { New approach to approval of clinical facilities put } \\
\text { into regulations }\end{array}$ & SANC & \\
\hline Set up co-ordinated clinical placements & CPCs \& services & NEIs \\
\hline
\end{tabular}

\section{Conclusion}

During the Nursing Summit held by the Department of Health in April 2011, the Clinical Model was accepted as the most efficient strategy for the improvement of the clinical preparation of nurses. Although the costing has not yet been done, one has to consider the comparative cost of incompetent nurses when deciding what is affordable. 


\section{References}

Al Kandari, F., Vidal, V.L., Thomas, D. 2009. Assessing clinical learning outcomes: A descriptive study of nursing students in Kuwait. Nursing and Health Sciences 11: 252-262.

Cowan, D., Norman, I. and Coopamah, V. 2007. Competence in nursing practice: A controversial concept: A focused review of literature. Accident and Emergency Nursing 15: 20-26. 


\section{Annexure 4.1: Job Descriptions}

\section{Clinical Preceptor}

\section{Job purpose:}

This is a person employed by higher education institutions to interact closely with allocated groups of students in a specific facility or group of facilities in order to optimise clinical learning of students in formal nursing programmes.

\section{Functions:}

- Inspire, invest in and support students;

- Facilitate the application of theory to practice, as well as encouraging higher levels of thinking;

- Support students in emotionally challenging environments in clinical practice and refer them where necessary;

- Maximise learning opportunities of students and facilitate exposure to appropriate learning opportunities;

- Promote the involvement of ward staff in the teaching of students;

- Teach by monitoring the student as he/she progresses towards the achievement of learning outcomes;

- Facilitate the role-modelling of complex clinical behaviour;

- Maintain a close working relationship with the academic staff and act as liaison between the service and the NEl;

- Participate in the formulation of clinical learning outcomes;

- Schedule working time over weekends, night duty and NEI vacation time as flexi- time systems;

- Be accessible to students by means of cell phone or pager.

\section{Requirements}

- Registered nurse;

- Current SANC certificate/licence to practice;

- 3 years clinical experience;

- Above average clinical, communication and interpersonal skills;

- Computer literacy;

- Positive attitude to self, students, nursing profession and clinical environment;

- Valid driver's licence

\section{Line management}

Report to: $\mathrm{CPC}$

Responsible for: None

Clinical Placement Co-Ordinator (CPC) 


\section{Job purpose:}

Registered nurse who develops and maintains a system of optimal placement of students from all programmes in a specific higher education institution in clinical facilities based on negotiated MOUs and good inter-agency relationships that allow for students to achieve programme outcomes and assist health services to maintain good quality care.

\section{Functions:}

- Monitor schedule of flexitime of preceptors;

- Schedule and chair monthly clinical co-ordination meetings;

- Evaluate clinical facilities for PPE status and monitor continued compliance;

- Monitor the quality assurance system for clinical training of students;

- Maintain compliance with SANC and CHE requirements with regard to clinical training facilities;

- Manage electronic placement software;

- Maintain existing and develop new relationships with clinical facilities for the placement of students;

- Recruit and organise training of preceptors;

- Facilitate the identification and appointment of CTAs;

- Develop and evaluate the comprehensive record keeping system with regard to clinical training.

\section{Requirements:}

- $\quad$ Registered nurse with an additional qualification in nursing education or management (preferably both);

- $\quad$ Proven clinical competence;

- Current SANC licence to practice;

- Detailed thinker and systematic worker;

- Above average interpersonal competence;

- Computer literate (Excel, data management systems);

- Driver's licence.

Report to: Principal of the NEI

Responsible for: Clinical Preceptors 


\section{Clinical Teaching Associate (CTA)}

\section{Job purpose:}

This is a specialist registered nurse who is appointed in an honorary capacity by an NEI, based on an MOU with the service facility to enrich the theoretical teaching and assessment of their students and enhance the capacity of the academic staff.

\section{Functions:}

- Do specialised and limited (no more than $10 \%$ of her/his time) teaching in formal programmes at NEls;

- Act as consultant for academics with regard to the teaching programme;

- Participate in assessment of students;

- Participate in research projects.

\section{Requirements}

- $\quad$ Deemed through peer review by the service and the NEI to be an expert nurse practitioner based on a professional portfolio where available;

- An education qualification will be an advantage. Recommend a basic in-house teaching skill to assist CTAs not previously involved in teaching with the principles of transferring knowledge in a logical, understandable manner. 